\title{
Cidadania em espaços (sub)urbanos: o Teatro do Oprimido no Alto da Cova da Moura e no Vale da Amoreira
}

\section{André Carmo*}

Resumo: A partir do estudo das atividades desenvolvidas por dois grupos comunitários de Teatro do Oprimido - DRK (Alto da Cova da Moura, Amadora) e ValArt (Vale da Amoreira, Moita) -, procura-se compreender como pode a cidadania, através da arte, contribuir para a construção de cidades mais justas, e quais os desafios e limites que este processo enfrenta. A pesquisa desenvolvida juntamente com os jovens pertencentes a ambos os grupos mostra que é sobretudo através da revelação e valorização de suas experiências, histórias e narrativas pessoais e contextuais no âmbito de sua intervenção social e política através do teatro, que se combatem alguns dos efeitos nefastos da urbanização contemporânea e que se diluem as fronteiras que separam estes bairros do seu entorno.

Palavras-chave: cidade, cidadania, arte, Teatro do Oprimido.

\section{Citizenship in (sub) urban spaces:}

\section{the Theater of the Oppressed in the Alto da Cova da Moura and in the Vale da Amoreira}

\begin{abstract}
From the study of the activities developed by two Theatre of the Oppressed communitarian groups - DRK (Alto da Cova da Moura, Amadora) and ValArt (Vale da Amoreira, Moita) -, we seek to understand how can citizenship through art contribute to the construction of more just cities, and what are the challenges and limits that this process faces. The research developed in conjunction with the young people participating in both groups shows us that it is mainly through the revelation and valorisation of their personal and contextual experiences, histories and narratives within the framework of their social and political intervention through theatre, that some of the nefarious effects of contemporary urbanization are fought, and the frontiers separating these urban spaces from their surroundings are diluted.
\end{abstract}

Key words: city, citizenship, art, Theatre of the Oppressed.

\section{Introdução}

ste artigo incide sobre as relações entre cidade e cidadania através da arte. A partir do estudo das atividades desenvolvidas pelos DRK e ValArt, grupos comunitários de Teatro do Oprimido pertencentes à rede dinamizada pelo GTO LX e constituídos, respetivamente, por jovens oriundos dos bairros do Alto

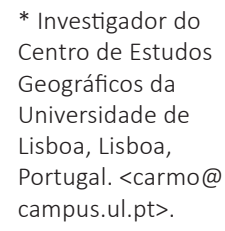


da Cova da Moura e do Vale da Amoreira, proc3ura-se compreender melhor como pode a cidadania através da arte contribuir para a construção de cidades mais justas, e quais os desafios e limites que este processo enfrenta. O que torna a segregação urbana um processo injusto? Quais as principais características da arte social e política? Em que medida a urbanização da injustiça se inscreve no Alto da Cova da Moura e no Vale da Amoreira? Como se processa a intervenção cidadã dos DRK e ValArt e quais os problemas abordados? Quais os limites e os desafios que enfrentam os seus protagonistas? Estas são algumas das questões abordadas neste artigo. Não tendo a pretensão de considerar que as respostas encontradas encerram definitivamente um campo de investigação tão complexo quanto este, considera-se, no entanto, que constituem mais um contributo para o seu desenvolvimento e aprofundamento.

Como pano de fundo para a análise, assume-se que os processos de urbanização capitalista geram múltiplas segregações socioespaciais e que algumas delas, sobretudo quando vistas a partir da habitação, dos espaços do existir e do ser, das residências e dos bairros, parecem corresponder à inscrição espacial da opressão, da desigualdade e da diferença (discriminatória), da marginalização e da estigmatização, da pobreza e da exclusão, em suma, da injustiça (Marcuse \& Kempen, 2002; Ribeiro, 2003; Wacquant, 2006; 2008). A urbanização socioespacial da injustiça é, aliás, um dos traços mais perversos dos processos de produção capitalista das cidades e metrópoles contemporâneas (Guerra, 2008; Merrifield \& Swyngedouw, 1996; Soja, 2000). A cidade é injusta porque, ao ser produzida na ótica do capital e não na dos cidadãos, algumas de suas segregações parecem corresponder à inscrição socioespacial de constrangimentos institucionais econômicos e culturais que tornam mais difícil a construção das "condições institucionais necessárias para o desenvolvimento, bem como para o exercício de capacidades individuais, de comunicação e cooperação coletivas" (Young, 1990: 39).

Apesar de hoje a lógica de produção da cidade enquanto mercadoria prevalecer como legado do desenvolvimento histórico do capitalismo, não existe nenhum fatalismo determinista nem qualquer mecânica causal pré-determinada subjacentes a tal trajetória. Na verdade, a cidade é um processo, um espaço social indissociável das múltiplas experiências humanas em constante devir, um "espaço que pode continuamente moldar-se e acomodar-se, mas deixando continuamente as marcas da sua transformação" (Negro \& Carvalho, 2010: 7). Contudo, a dimensão básica da mudança urbana, como, aliás, sugere Manuel Castells (2003), assenta-se no antagonismo e na tensão existentes entre diferentes grupos, classes sociais e atores históricos relativamente aos significados do mundo urbano, à relação entre forma espacial e estrutura social e ao destino das cidades. Consequentemente, 
a cidade pode - e deve - ser compreendida enquanto espaço eminentemente político, isto é, lugar e palco da cidadania. Por exteriorizarem raízes etimológicas partilhadas - civitas -, cidade e cidadania emergem, na tradição do pensamento ocidental, como termos e realidades interligadas expressando, simultaneamente, um modo de habitar e uma forma de participar e intervir no mundo (Nawratek, 2011). Assim, considera-se, na esteira de Jordi Borja (2003), que a cidadania é uma conquista - permanente e cotidiana -, um processo que deve ser exercido pelos próprios protagonistas, e não um estatuto atribuído por uma autoridade investida desse poder.

Para os membros do Laboratory of Insurrectionary Imagination (2010), a arte teve sempre utilidade para alguém. Como mercadoria circunscrita aos limites do mercado torna-se, fundamentalmente, um amplificador estético dos valores dominantes (ver Fortuna et alii, 1998/1999; Lopes, 2011; Vidal, 1997). Mas pode-se olhar a arte de outra forma, colocando o enfoque sobre a arte que escapa às regras, normas e convenções do mundo artístico e se transforma em processo coletivo de criatividade instituído a partir da materialidade (socioespacial) da vida cotidiana. A trama que se entretece entre cidadania e arte remete, assim, para uma libertadora negação da arte-mercadoria, para a existência de envolvimentos, práticas e intervenções cívicas e políticas emancipatórias que, mediante a arte, procuram transformar o mundo (ver Duncombe, 2008; Kershaw, 1992). Vista sob esse prisma, a arte contribui decisivamente para problematizar e refletir criticamente a hegemonia dominante, questionando a autoridade, fomentando a dissidência e contribuindo para tornar visível o que o consenso dominante tende a obscurecer, subalternizar ou ignorar (Mouffe, 2007; Selz, 2006). Por outras palavras, visa dar uma voz àqueles que se encontram silenciados pela hegemonia existente e, ao subvertê-la, contribuir para a construção de imaginários sociais alternativos, novas subjetividades políticas e novas espacialidades.

\section{Coordenadas metodológicas}

Este estudo adotou uma abordagem integrada, recorrendo simultaneamente a instrumentos metodológicos de natureza quantitativa e qualitativa. A informação usada para caracterizar e conhecer mais profundamente o Alto da Cova da Moura e o Vale da Amoreira foi recolhida em 2011 através da aplicação de um questionário, durante um período de aproximadamente dois meses no primeiro bairro e três no segundo. Os membros das equipas de inquirição, cinco no Alto da Cova da Moura, 12 no Vale da Amoreira, eram jovens residentes nos respetivos bairros, condição absolutamente fundamental para que o procedimento tivesse sido bem-sucedido e as taxas de não resposta relativamente baixas. 
1. Ver <http:// www.raosoft.com/ samplesize.html>.
Com recurso a uma aplicação on-line designada sample size calculator ${ }^{1}$, a dimensão da amostra foi calculada a partir do universo censitário de 2001, admitindo uma margem de erro de 5\% e um nível de confiança de 95\%. É importante salientar, ainda, que os dados populacionais coligidos pelas instituições que trabalham cotidianamente no terreno, em ambos os bairros, são substancialmente superiores aos dos censos, aspeto a que não serão obviamente estranhos as suas próprias agendas reivindicativas, o peso relativamente elevado dos residentes indocumentados e a grande mobilidade de uma parte substancial da população residente nesses bairros. Para além disso, dado que os membros dos DRK e ValArt são constituídos exclusivamente por jovens, para promover uma maior comparabilidade entre os contextos geográficos e os protagonistas decidiu-se circunscrever o universo de referência à população residente com idades compreendidas entre os 15 e os 34 anos de idade.

Por conseguinte, no Alto da Cova da Moura foram inquiridos 293 jovens e 352 no Vale da Amoreira. Dado que o método de seleção dos inquiridos não é aleatório, mas sim decorrente das opções tomadas pelos membros das equipas de inquirição no terreno e das suas redes locais de sociabilidade, a amostra usada não é estatisticamente representativa. Não obstante, dada a dimensão da amostra e o fato de terem sido definidos alguns critérios para a "movimentação" no terreno das equipes de inquiridores (ver Vicente et alii, 2001), ou seja, de, no decurso do trabalho de campo, terem sido dadas indicações para que fossem considerados os espaços residenciais de cada um dos bairros em sua totalidade e se aplicassem os questionários em diferentes dias da semana e em diferentes horários, considera-se que os resultados obtidos são suficientemente robustos e oferecem um retrato ilustrativo dos vários aspetos nele contemplados.

No que toca aos DRK e ValArt, a base para a reflexão foi o levantamento dos testemunhos articulados (ver Nunes, 2001) de alguns dos seus membros. Considera-se que a compreensão do papel desempenhado pelos protagonistas enquanto sujeitos e não meros objetos de estudo implica necessariamente uma abordagem intensiva, construída a partir de uma relação de estreita proximidade e diálogo que com eles se estabelece. É importante salientar que essa técnica é usada de modo experimental, não existindo uma separação rígida entre as entrevistas semiestruturadas, as histórias de vida e os testemunhos (ver Benítez, 2010; Haig-Brown, 2003; Randall, 2002; Poirier et alii, 1999), tratando-se de um contínuo. Aquilo que os diferencia é, sobretudo, sua natureza concreta, sendo os testemunhos articulados a técnica que mais respeita a voz dos sujeitos investigados. Ao fazê-lo, procura também facilitar o reconhecimento da natureza eminentemente política da vida cotidiana da gente comum e interrogar/problematizar a autoridade (soberana) do 
sujeito que investiga. A autorização que obtivemos para usar, neste trabalho, as identidades reais dos protagonistas revela-se, a este respeito, particularmente importante.

A recolha dos testemunhos articulados, tarefa empreendida entre março e abril de 2014, foi feita de modo a possibilitar a emergência de vozes outras que não as do investigador responsável por este estudo sem que, no entanto, deixe de ser este a ter a iniciativa e a despoletar a curiosidade interrogativa. Nos testemunhos articulados, há mais espaço para a reflexividade do sujeito com quem se procura dialogar. Se a realidade é multifacetada, assim tem de ser a história que dela se procura contar. Não faria sentido descrever um caminho de sentido único. Como sugere João Nunes (2001), o testemunho articulado baseia-se no dialogismo e na multivocalidade, na tolerância, na experimentação e na hibridação discursivas; em suma, numa concessão contra-hegemônica do conhecimento que se pretende aqui afirmar, em linha com a geografia urbana crítica que norteia este estudo.

\section{Arte social e política:}

\section{para uma estética da justiça}

Mouffe et alii (2001) afirmam que qualquer manifestação artística tem uma dimensão política e que a distinção entre arte política e não política é inadequada, uma vez que a arte segue sempre uma de duas vias: ou contribui para a reprodução do senso comum ou para a sua desconstrução crítica. Em outras palavras, a distinção entre arte política e não política é falaciosa pois, quer se trate de práticas artísticas que desempenham um papel importante na construção e manutenção de uma determinada ordem simbólica, quer visem à confrontação e à desestabilização dessa mesma ordem, estamos sempre em presença de manifestações políticas. Em ambos os casos, trata-se de intervenções de natureza eminentemente política (ver Masset, 2011). Não obstante, é sobretudo nesta última que as tensões existentes entre a realidade social e política mais vasta e o espaço da produção de arte se tornam mais intensas e problemáticas (Schechner, 2006).

É justamente neste espaço epistemológico que esta investigação se posiciona, assumindo que a arte social e política implica necessariamente um alargamento do campo de intervenção, que se prolonga por múltiplos espaços sociais, de modo a contrariar aquilo que Mouffe (2007) designa de "programa de mobilização social total do capitalismo". O ativismo artístico procura assim obstaculizar as circunstâncias e os ambientes imaginários favoráveis à reprodução desse mesmo programa (ver Bavo, 2007; Kanngieser, 2010; Meskimmon, 2011). Efetivamente, embora as práticas artísticas possam contribuir para o combate contra a dominação capita- 
lista, é imprescindível que estejam articuladas com uma compreensão de dinâmicas sociais e políticas democráticas, algo que só pode ser alcançado através do reconhecimento de que a cidadania se assenta em múltiplos antagonismos e contingências. Por conseguinte, a questão crucial prende-se às possibilidades de (re) configuração da arte social e política, ou seja, às diferentes maneiras através das quais as práticas artísticas podem contribuir para questionar a hegemonia dominante, promovendo a construção de identidades críticas, reflexivas e atuantes (ver Abbing, 2002; Moore, 2004).

De acordo com a perspectiva agonística (ver Mouffe, 2000; Laclau \& Mouffe, 2001), a arte social e política é precisamente aquela que fomenta a dissidência, questiona a autoridade e procura tornar visível aquilo que os consensos dominantes tendem a obscurecer e, amiúde, ignorar. No quadro da hegemonia existente, a arte social e política traduz assim um conjunto vasto e diversificado de práticas artísticas que procuram dar voz àqueles que normalmente não a têm (Manchev, 2011). Como assinala Chantal Mouffe, os artistas podem ainda hoje desempenhar um papel importante no combate hegemônico subvertendo essa hegemonia e contribuindo para a construção de novas subjetividades. Na verdade, este foi sempre o seu papel e apenas a ilusão modernista da posição privilegiada do artista nos levou a pensar doutra forma. Uma vez abandonada esta ilusão, juntamente com a concessão política revolucionária que a acompanha, podemos verificar que "as práticas artísticas críticas representam uma dimensão importante da política democrática" (Mouffe, 2007: 5).

Evidentemente, isto não significa que as artes podem, por si só, transformar a sociedade. Seria, aliás, um erro pensar que o ativismo artístico pode ser o "coveiro" da hegemonia neoliberal. Articulado com outras manifestações de cidadania e instrumentalmente mobilizado por elas pode, no entanto, constituir um contributo relevante, como quando a música, o ritmo e a dança são usados para imprimir intensidade a um protesto e construir temporariamente uma identidade coletiva (ver Bishop, 2006; Larsen, 1999/2006; Tucker, 2010).

De acordo com Jacques Rancière (2002; 2009), o mundo atual é concebido como espaço adverso no âmbito do qual é comum se falar de crise da arte ou de sua captura e subjugação por intermédio de um discurso acrítico e de uma poderosa e subtilmente urdida lógica de silenciamento e ofuscação da dissidência pelos poderes dominantes. A arte social e política, no entanto, parece estar relacionada a processos capazes de criar novos modos de percepção e novas subjetividades políticas; traduz a delimitação dos espaços e tempos da visibilidade e da invisibilidade, da voz e do silêncio, determinando, ao mesmo tempo, aquilo que está em causa na cidadania 
enquanto política em ato, os espaços-tempos que ocupa, as suas propriedades e possibilidades.

Com efeito, na esteira de Rancière (2009: 45), defende-se que a arte social e política constitui um "tipo de arte que procura aumentar a consciência dos mecanismos de dominação para transformar o espectador num agente consciente de transformação do mundo". A arte social e política implica a construção de espaços e relações que, em si mesmas, reconfiguram material e simbolicamente os espaços comuns e partilhados. Por conseguinte, constroem-se situações efêmeras e indeterminadas, transformam-se os papéis tradicionalmente atribuídos a atores e espectadores e assiste-se a uma reconfiguração material e simbólica dos lugares. Em suma, o ativismo cultural, em suas diferentes declinações, tenta (re)organizar o desejo e as subjetividades sociais e políticas.

\section{O Teatro do Oprimido:}

\section{anatomia de uma arte cidadã}

O Teatro do Oprimido (TO) é um sistema teatral, uma expressão de arte social e política cuja natureza instrumental relativamente à construção da cidadania é histórica e socialmente reconhecida. Sendo a sua origem o trabalho pioneiro do dramaturgo brasileiro Augusto Boal (2001; 2009), que remonta à década 1960, é hoje

\footnotetext{
um corpo de conhecimento filosófico complexo, interdisciplinar e multivocal que engloba, entre outras coisas, o trabalho de Paulo Freire e Bertolt Brecht, carnaval e circo, o teatro avant-garde brasileiro de meados do século vinte, as influências de teóricos políticos como Hegel e teóricos estéticos como Aristóteles (Schutzman \& Cohen-Cruz, 2006: 1).
}

A singular capacidade do TO para (re)politizar facetas da realidade social às quais normalmente não se atribui qualquer relevância social e política, isto é, que são consideradas apolíticas e se encontram afastadas de um qualquer espaço público, foram exploradas por Cohen-Cruz (2006). Para esta autora, o ponto de partida do TO, para o combate à opressão e para a resolução dos problemas que the estão associados, é a partilha de histórias, narrativas e trajetórias pessoais. Com efeito, o potencial político de uma narrativa pessoal encontra-se não em seus conteúdos ou nas matérias sobre as quais incide, mas sim em sua capacidade de (re)posicionar mesmo o menos poderoso dos indivíduos-objetos como sujeito-ativo.

O próprio ato de verbalizar uma (contra)narrativa pessoal publicamente representa, aliás, não apenas o principiar de uma relação com outras pessoas, mas também 
um passo rumo a estratégias de agenciamento social e político que, como é sabido, passam, em grande medida, pela revelação do que normalmente permanece invisível e/ou silencioso. Ao colocar o enfoque sobre as opressões, os sujeitos deixam de experienciar as suas histórias como limitações ou constrangimentos de natureza privada e pessoal e passam a percebê-las enquanto problemas inseridos num quadro mais vasto de contextos e de relações socioespaciais. Na verdade, os resultados mais tangíveis do TO ocorrem sobretudo no âmbito interpessoal, ou seja, naquilo que diz respeito aos protagonistas eles mesmos, ao modo como se relacionam com outras pessoas, em contextos familiares, laborais ou outros (Schutzman, 1994).

As histórias pessoais politicamente enquadradas, isto é, resultando de um compromisso instável entre intimidade e distanciamento, tornam-se assim os pilares fundamentais para o desenvolvimento da experiência de TO. É importante salientar também o fato de o TO englobar um conjunto bastante diversificado de técnicas teatrais, sendo a mais disseminada o teatro-fórum, cuja gênese remonta às experiências com aquilo que Boal chamava dramaturgia simultânea, isto é, formas de produção teatral assentes nas vivências cotidianas das pessoas comuns.

Com efeito, o teatro-fórum tem como objetivo a criação de uma cena na qual o protagonista se revela incapaz de alcançar e/ou satisfazer os seus objetivos, necessidades ou desejos devido à existência de opressões. Sempre que considerem necessário ou pertinente, os membros da audiência podem suspender o desenrolar da ação dramática, substituir o protagonista e improvisar o comportamento alternativo que considerem mais adequado para lidar com elas. Este momento é entendido enquanto ensaio para a transformação social, conferindo esta capacidade para o espectador transgredir as convenções teatrais, intervindo diretamente no desenrolar dos acontecimentos, tornando-se assim protagonista da ação dramática, a que Boal chamaria metaxis (do grego methexis, termo usado por Platão e Aristóteles para significar entre + dentro, através, trânsito) (ver Linds, 1998). É preciso, no entanto, sublinhar que, se, por um lado, o teatro-fórum assenta-se em narrativas deliberadamente incompletas a partir das quais se procura ensaiar e descobrir alternativas dinâmicas ao caminho seguido que é experienciado enquanto opressão; por outro, a audiência é geralmente constituída por pessoas que reagem a partir de um lugar de identificação e empatia e não de diferenciação e distanciamento.

[Efetivamente,] no teatro-fórum, quando a história é representada, deixa de ser apenas a narrativa de uma pessoa. A história de cada pessoa é apenas a matéria-prima a partir da qual a cena, com a qual toda a gente no grupo se pode identificar, é criada. Em teste- 
munhos acerca de opressões sociais, o narrador fala não apenas em nome próprio, mas também em nome de um conjunto mais abrangente de pessoas que lidam com tratamentos injustos semeIhantes (Cohen-Cruz, 2006: 107).

Através da ascese - o movimento que a partir de um dado fenômeno particular ascende e tenta passar da singularidade à pluralidade de modo a compreender o seu lugar no mundo -, o teatro-fórum ajuda a reposicionar as trajetórias pessoais como expressões partilhadas por determinados grupos sociais. Este trabalho de abstração não pode, porém, deixar de ser feito de modo concreto e focado nas experiências vividas das pessoas, para não perder a sua capacidade de mobilização coletiva.

\section{Alto da Cova da Moura e Vale da Amoreira: retratos da injustiça na Região Metropolitana de Lisboa}

\section{A Região Metropolitana de Lisboa}

é um grande conjunto de ilhas - umas com excelentes condições de vida e outras em que a exclusão social é uma realidade ou um risco iminente (André \& Vale, 2012: 218).

O processo de metropolização da região de Lisboa, enquanto expansão da urbanização a partir de um núcleo central, contribuiu para a (re)produção de espaços urbanos marcados pela sobrerrepresentação do desemprego, do insucesso escolar, das baixas qualificações, pela condição periférica, marginalidade e estigmatização. Como sublinham Jorge Malheiros, Lia Vasconcelos e Francisco Alves, sendo

muitas vezes habitados por um número significativo de famílias imigrantes, [estes espaços são] também marcados por um certo isolamento geográfico, social e simbólico face ao resto da cidade, transformando-se em no go areas (Malheiros et alii, 2007:24).

De uma forma mais contundente, Luís Capucha defendeu que

pelas suas imagens, pelas condições em que se encontram do ponto de vista urbanístico, pela escassez dos equipamentos e serviços que os servem, pelas dificuldades materiais em que se encontra a maioria dos moradores, muitas vezes ainda pela segregação de que são alvo - por razões de desprezo e ostracismo às vezes sobre a forma de racismo -, os bairros pobres das grandes cidades e das suas periferias tendem a constituir contentores de pobreza e exclusão social particularmente problemáticos (Capucha, 2000: 11). 
O Alto da Cova da Moura e o Vale da Amoreira são dois bairros cuja origem e desenvolvimento assumem contornos algo distintos. A gênese do primeiro é mais complexa, incluindo vários elementos que tradicionalmente se encontram no quadro de constituição dos bairros clandestinos (ex: ocupação de parcelas de terreno associada a uma divisão informal do território; edificação, em diversas partes do bairro, de construções unifamiliares; consolidação progressiva do edificado, construído de forma definitiva com recurso a concreto e alvenaria de tijolo) sem que, no entanto, ocorra aquisição de lotes por parte dos residentes (i.e. não são proprietários formais). A situação do Vale da Amoreira, por seu turno, está intimamente relacionada à lógica da produção de habitação social na fase de alargamento da oferta desta, na sequência das transformações introduzidas na política de habitação na década de 1960 que conduziram à edificação de diversos bairros sociais de grande escala. Tendo em consideração estas diferenças, cada um destes bairros será examinado separadamente, sob os pontos de vista da sua evolução histórica e da caracterização econômica e cultural do seu tecido social.

O Alto da Cova da Moura localiza-se na parte oriental do concelho da Amadora, ocupa um espaço de fronteira entre as freguesias da Buraca (maioritariamente) e da Damaia. Apesar das dificuldades no apuramento de sua dimensão populacional, os dados mais recentes apontam para valores globais na ordem dos seis mil habitantes, sendo de realçar a existência de uma estrutura demográfica bastante mais jovem do que a envolvente, existindo cerca de $45 \%$ da população com idade inferior a 24 anos (Malheiros et alii, 2006; Vasconcelos, 2007). Em meados da década de 1970, já a maior parte da população de origem africana desempenhava funções indiferenciadas, os homens nos setores da construção civil e indústria e as muIheres nos serviços de limpeza e trabalhos domésticos, encontrando a população portuguesa ocupação em trabalhos semiqualificados (ex: enfermeiros, funcionários públicos, operários, polícias, taxistas) (Horta, 2004). Por conseguinte, desde há muito se assiste à etnicização dos segmentos mais desqualificados do mercado de trabalho e à sua segmentação etnolaboral. Hoje, embora com particular incidência na comunidade africana, a população residente no Alto da Cova da Moura encontra-se empregada nos setores mais mal pagos, precários e inseguros da estrutura laboral, os rendimentos das famílias são baixos, as perspectivas de mobilidade social ascendente diminutas e o horizonte de possibilidades futuras bastante estreito e afunilado. Efetivamente, marcado pela privação econômica e pela discriminação e/ou exclusão de base cultural (étnico-racial), o bairro apresenta alguns atributos comuns a muitos espaços (sub)urbanos, paisagens étnicas em que se inscreve e reproduz "a expressão material extrema da pobreza, exploração e segregação" (MaIheiros et alii, 2007: 142). 
Paralelamente, assiste-se também, na sociedade portuguesa, a uma maior mediatização de espaços urbanos como o Alto da Cova da Moura, associando-os a comportamentos desviantes (ex: criminalidade e tráfico de drogas), à exclusão e ao racismo, à marginalidade e ao desenraizamento, à delinquência, ilegalidade e violência (ver Silva, 2000). O bairro é reduzido a uma construção imaginária estereotipada que se torna hegemônica e é difundida e amplificada mediaticamente, na qual os seus habitantes, sobretudo os jovens, são vistos como seres potencialmente ameaçadores para a ordem social vigente. Como sublinham Malheiros, Vasconcelos e Alves,

\begin{abstract}
é um espaço fortemente retratado pelo estigma e associado à violência. São constantes as rusgas policiais e as crianças e adolescentes vivem aí a sua condição híbrida de serem social e culturalmente invisíveis. Os jovens, mesmo quando entretidos nos seus afectos e dramas pessoais, são percebidos como pessoas violentas e perigosas que, ao aproximarem-se de alguém que passa, provocam rejeição, medo e agressividade (Malheiros et alii, 2007: 200).
\end{abstract}

Assiste-se, pois, ao processo de "guetização" do Alto da Cova da Moura. Alguns dos dados apurados a partir dos questionários realizados nesse bairro, apontam no mesmo sentido. Por exemplo, 54\% dos inquiridos consideram que é difícil (25\%) ou muito difícil (29\%) viver com o rendimento atual e $87 \%$ autoposicionam-se na metade inferior da escala social. Por outro lado, a maior parte (54\%) dos inquiridos afirma ter sido vítima de discriminação por viver no Alto da Cova da Moura, sendo a procura de emprego (71\%), o relacionamento com a polícia (68\%) e a frequência de estabelecimentos comerciais (56\%), os contextos discriminatórios mais referenciados. Igualmente relevante é o fato de "pobreza e desemprego" terem sido considerados um dos principais problemas do bairro por $88 \%$ dos inquiridos, referindo $58 \%$ às condições de habitação, 40\% à estigmatização e à imagem e 39\% à insegurança e à criminalidade. Efetivamente, a partir do retrato esboçado, é possível olhar para o Alto da Cova da Moura enquanto espaço urbano profundamente marcado por um conjunto de características e dinâmicas econômicas e culturais que têm efetivamente dado uma configuração socioespacial à injustiça.

No que toca ao Vale da Amoreira, a população residente em 2011 era de aproximadamente 10 mil habitantes, embora nalguns diagnósticos e estimativas produzidos por associações locais os valores sejam mais elevados. Mais de $40 \%$ da população apresentam uma idade inferior a 25 anos, tornando o Vale da Amoreira a freguesia mais jovem do concelho da Moita. Igualmente relevante é o fato de uma percentagem muito significativa da população (45\%) não ter nacionalidade portuguesa, sendo predominantes as nacionalidades cabo-verdiana (15\%), angolana (10,3\%) e guineense (10\%) (GAT, 2006). 
Foi sobretudo a partir do 25 de abril de 1974 em diante que a face do Vale da Amoreira viria a ser mais profunda e estruturalmente alterada e que aspetos como o desemprego, a dificuldade de acesso a serviços, o desenraizamento cultural, a discriminação, o baixo nível de escolaridade, a precariedade laboral e os baixos rendimentos, a desestruturação familiar e as dificuldades de acesso a bens essenciais passaram a fazer parte de sua paisagem social (Santos, 2011). O inquérito realizado mostra que, efetivamente, a pobreza e o desemprego encontram-se entre os principais problemas do bairro para $70 \%$ dos inquiridos, salientando $60 \%$ a insegurança e a criminalidade, $41 \%$ o consumo e o tráfico de estupefacientes e $35 \%$ as condições de habitação. De um ponto de vista econômico, em sentido lato, para além de uma parte importante da população residente se encontrar inativa $(28,4 \%)$, indiciando um peso importante da economia informal ou subterrânea, predominam os trabaIhos pouco ou nada qualificados, mal remunerados, temporários e/ou precários, salientando-se o setor da construção civil, no caso dos homens, e dos serviços domésticos e de limpeza, entre as mulheres.

No que diz respeito às representações simbólicas do Vale da Amoreira, à sua imagem, constata-se que esta é fundamentalmente construída externamente (de fora para dentro), inscrevendo-se neste espaço urbano uma certa ideia de marginalidade associada às questões da insegurança e do tráfico de drogas, que, por constituírem o seu referencial identitário mais marcante, é interiorizada e reproduzida, levando ao aprofundamento de suas fronteiras físicas e simbólicas relativamente ao entorno. Assiste-se, pois, ao desenrolar de um processo de autofechamento, uma certa "guetização" autoimposta e fortemente protagonizada pelos jovens residentes. Apesar de ser considerado um espaço de solidariedade e forte sentido comunitário, são também projetadas sobre o Vale da Amoreira, a partir do exterior, um conjunto de imagens negativas relacionadas, fundamentalmente à criminalidade, à violência e às drogas que são profundamente estigmatizantes (ver Padilla, 2011). Por conseguinte, não é de todo surpreendente que $76 \%$ dos inquiridos se autoposicionem na metade inferior da escala social e 52\% considerem que é difícil (36\%) ou muito difícil (16\%) viver com o rendimento atual. Não obstante, e em flagrante contraste com o Alto da Cova da Moura, apenas $16 \%$ se sentiram discriminados pelo fato de residirem no Vale da Amoreira, destacando-se a procura de emprego (48\%) e o espaço público de rua (38\%) como contextos discriminatórios mais referenciados. 


\section{DRK e ValArt:}

\section{o Teatro do Oprimido como instrumento de cidadania}

Olha-se agora para os protagonistas num sentido mais concreto e humanizado, isto é, para os jovens ${ }^{2}$ que corporizam o TO através de suas práticas e intervenções nos diferentes espaços urbanos em que se movem e vivem. O modo como suas vivências e trajetórias pessoais se entrecruzam com o TO enquanto instrumento de cidadania é, pois, o foco desta investigação ${ }^{3}$. Na generalidade dos casos, os jovens colocam em evidência o fato do TO surgir como atividade singular nos espaços a partir dos quais edificam suas experiências de vida cotidiana. Efetivamente, a prática concreta do TO, em suas múltiplas dimensões constitutivas, e a partir de suas vivências socioespaciais, permitiu aos jovens consolidarem, progressivamente, sua opinião acerca do método teatral criado por Augusto Boal, bem como a importância que os contextos geográficos assumem para a construção de sua intervenção cidadã através da arte. Assim, quando questionada acerca da importância que os espetáculos dos ValArt atribuem ao Vale da Amoreira, quase como se de um laboratório urbano se tratasse, Gisela Santos é peremptória:

Sim, baseávamo-nos muito naquilo que realmente víamos e que sentíamos que era um problema. Inicialmente começamos por nós, mas também a ver [que problemas se manifestavam] no nosso "meio" e era daí que vinham os nossos espetáculos.

De modo bastante vívido, descreve ainda o processo que viria a resultar no "X-Perar":

Inicialmente, nós queríamos falar da gravidez na adolescência, porque no Vale da Amoreira é algo que vemos muito. Não só no Vale, mas aí é algo que nós víamos todos os dias. Muitas miúdas de 14 anos e um pouco mais velhas, nessas idades que achamos que é mais complicado, estavam grávidas e nós começamos a pensar que isso era um problema e se calhar era bom começar a falar disso, até porque tínhamos amigas, vizinhas, primas, que estavam grávidas. Inicialmente o espetáculo era isso, mas depois, quando começamos a conversar e a debater, chegamos à conclusão que não era só isso. Era o que está por trás da gravidez, ou porque é que vem uma gravidez. Será que também tem a ver com a posição que a mulher tem na sociedade? O que é a mulher? $\mathrm{E}$ o homem? Não é só a gravidez, mas sim tudo o que envolve a sexualidade e a igualdade.
2. Os nomes que se apresentam de seguida, são de jovens participantes nos dois grupos de TO que foram objeto de análise nesta investigação.

3. Por motivos de economia de espaço e coerência interna deste artigo, optouse por deixar de fora algumas experiências de TO desenvolvidas por ambos os grupos (ex: DRK- "Sonhos de Papel!" e ValArt - "TB Linha"), que exploram outras possibilidades de utilização do TO como instrumento de cidadania, tais como o teatro legislativo, que, até certo ponto, demonstram que este pode intervir de um modo que vai para além das questões de natureza eminentemente interpessoal.

Vânia Lopes corrobora esta leitura afirmando: 
Sim, porque é onde eu e o grupo estamos inseridos [...]. Às vezes começa no particular e depois vai para um sentido mais macro, um problema que começa aqui na minha comunidade, acabando por acontecer em toda a sociedade.

Também no Alto da Cova da Moura o processo de produção artística apresenta contornos semelhantes. Como salienta Reginaldo Spínola, "é tudo realidade nossa mesmo [...] são realidades nossas". A propósito do espetáculo "InTerEsse" afirma:

Foi uma peça bué marcante para nós, sobre o mundo da droga no bairro e a não perpetuação da vida dos nossos pais. Nós estudamos, sabemos falar português [...] porque não estudar, acabar a escola e sermos alguém na vida? A nossa pergunta mais forte é mesmo esta? Dizíamos muito no início, ser alguém é ter casa, dinheiro, é ter. O materialismo na nossa cabeça. Mas não pensávamos no ser. Através desta peça queríamos ser. Isso é bué forte. Não optar por vender droga que é a maneira mais fácil aqui no bairro e optarmos por ser.

Esta inscrição socioespacial reflete-se também nas estratégias de intervenção delineadas pelos grupos como atestam Reginaldo - "onde queremos intervir é nos bairros porque os problemas são idênticos" - e Vânia Lopes:

Este ano [2014] pensei em concentrar-nos aqui no Vale da Amoreira e faz sentido trabalhar aqui com a nossa comunidade porque é onde vivemos e sentimos os problemas.

Por outro lado, no que diz respeito ao modo como arte e política se entrecruzam virtuosamente no TO, Vânia sublinha:

A arte acaba sempre por vir depois. Primeiro edificas, analisas um problema, tu questionas, falas sobre aquilo e usas a arte [...] a arte é uma ferramenta, mas podes ver a arte noutro sentido porque ela te ajuda a que as coisas também possam sair, por exemplo, nas dinâmicas que usamos nos jogos em que olhas como um simples jogo, mas o jogo tem um objetivo. Nas formações às vezes começas com um jogo, está tudo muito envergonhado, mas depois começas a fazer um jogo e quando dás por ti já está tudo super entusiasmado. Começas pela arte para estimular, para que as pessoas se sintam mais à vontade, mas também podes ver enquanto processo de, eu sinto isto, quero trabalhar para isto, quero mudar porque isto tem consequências muito negativas na minha vida, isto e aquilo, e trabalhas nesse sentido. Tens as duas visões.

Sempre mais conciso, William Brandão assinala também que 
o teatro-fórum não é como um teatro normal, é um teatro que intervém com o público e por isso é bom. Expomos um problema que é nosso, que é nosso sim, e o público pode ajudar a resolver esse problema e isso é bom.

De modo similar, Adriano Diouf afirma:

Quando eu percebi que poderia ter essa ferramenta de dar a voz a outras pessoas foi quando eu senti que poderia ser mais útil. Não bastava ser um confronto, isso faz-se muito, mas o teatro-fórum podia ajudar a maneira de tentarmos fazer um melhor confronto. Porque confrontar toda a gente faz e isso é o mais fácil, queremos partir para a ignorância. O TO talvez me tenha ajudado a gerir isso e [...] ajudou-nos muito a chegar às pessoas, a perceber que não somos os únicos com o mesmo problema e que existem várias pessoas com ele.

Emerge, aqui, a importância atribuída à revelação, ao lançar luz sobre questões e problemas que são experienciados na primeira pessoa, e que por isso se inculcam nas biografias dos diferentes protagonistas que, em si mesmos, são constitutivos dos espaços sociais em que esses mesmos problemas se manifestam e (re)produzem. Numa ótica semelhante, Adriano Diouf coloca em evidência a ideia de que o TO é muito mais do que apenas teatro. Em suas palavras, o TO é muito mais porque

- Augusto Boal quando pegava atores para representar problemas de sem-abrigo as pessoas aplaudiam e não sentiam o problema, embora se emocionassem, não percebiam a essência da dor. Mas quando ele pegou os próprios sem-abrigo para representar já existia um grande confronto [...] existem várias coisas no mundo que não posso dizer que foi o TO que ajudou [a resolver] mas a nós ajudou-nos imenso porque a maneira de vermos mais problemas, não oprimir, perceber onde estamos a ser oprimidos [...] passar a ser opressor é um passo, para deixar de ser oprimido batalha-se.

É justamente através das suas produções teatrais que os jovens tornam a arte um instrumento de cidadania. E fazem-no de formas bastante diversificadas. A pluralidade é, efetivamente, um dos traços mais característicos de sua produção e apropriação artístico-política (Pais, 2010). Por outro lado, o desenrolar do processo criativo conduz, por vezes, a caminhos que inicialmente não haviam sido considerados. Há, pois, um caminho que se vai fazendo e cujo itinerário se pode refazer e adaptar às influências decorrentes da relação dialógica que se estabelece entre os grupos e as audiências, os (espect)atores que participam nos espetáculos. Frequentemente, são também referidos pequenos episódios, pequenos indícios de mudança e 
transformação ligados à intervenção levada a cabo pelos diferentes grupos que, não obstante, são considerados marcantes e decisivos. William Brandão considerou que a mudança é também visível

quando acaba um espetáculo e as pessoas nos dizem, fogo, há pouco tempo passei por isso e agora já me deste uma dica de como resolver esta situação.

Quando se procura perceber o que conseguem vislumbrar os jovens para o futuro de sua intervenção cidadã através da arte, não existem grandes certezas, para além do reforço do papel desempenhado pelos grupos nos seus respetivos contextos geográficos, dotando-os de maior influência e visibilidade social e política. Não obstante, Adriano Diouf, refletindo sobre os desafios futuros e os limites ao que os ValArt podem fazer afirma:

Acho que temos todos de abrir mais a mente porque somos todos afetados pela cultura em que vivemos, pelo meio em que vivemos, vários fatores que temos de conhecer melhor [...] não existe um limite porque nós podemos ir até onde queremos. Onde a gente quer é sempre mais à frente [...] até onde queremos é a nossa mente que abre para tudo. No entanto, não nos basta querer resolver um problema da nossa comunidade, há toda uma avalanche por conhecer.

Mesmo que inadvertidamente, Adriano acaba por colocar em evidência uma das tensões que hoje, como no passado, perpassa muitas experiências de cidadania, designadamente a que se estabelece entre as diferentes possibilidades que se abrem devido à ação cidadã e os múltiplos obstáculos e entraves à sua materialização concreta. Por outras palavras, as circunstâncias existenciais destes jovens protagonistas, sujeitos políticos em construção que fazem das artes o seu instrumento de cidadania, influenciam aquilo que podem, efetivamente, ser capazes de transformar. O modo como - lembrando uma feliz expressão de André Correia (2003) - a arte se "entretece com a vida" destes jovens, assume pois diferentes configurações. Efetivamente, cada um dos jovens interpreta e avalia diferenciadamente o seu percurso e a sua experiência pessoal. No entanto, parece assistir-se ao desenvolvimento de uma maior (mais profunda, densa e qualificada) consciência crítica em termos políticos e cidadãos por parte dos jovens, que encontram na arte o estímulo para uma maior intervenção cidadã e motivação para o envolvimento nos processos que visam mudar relações sociais e de poder. A consciência de que é possível fazê-lo "a partir do bairro" e recorrendo à arte como instrumento, torna-se efetivamente uma realidade. 


\section{(Re)considerações finais}

Neste artigo, procurou-se questionar e problematizar as possibilidades de a cidadania - política em ato - poder promover a resistência, contrariar e, em última instância, transformar a cidade injusta, ou seja, combater as desigualdades econômicas e as discriminações de raiz cultural constitutivas da segregação urbana. No que diz respeito aos espaços urbanos a partir dos quais os protagonistas desenvolvem a sua intervenção - Alto da Cova da Moura e Vale da Amoreira -, o estudo evidencia que estes correspondem efetivamente a espaços segregados nos quais a urbanização da injustiça se inscreve e (re)produz. A conjugação de condições econômicas adversas (ex: desemprego, precariedade, baixos rendimentos) com atributos culturais que traduzem uma posição desfavorável no contexto da sociedade maioritária (ex: sobrerrepresentação de jovens afrodescendentes) define, assim, e apesar das ligeiras diferenças encontradas entre ambos, muitas das vivências cotidianas encontradas no Alto da Cova da Moura e no Vale da Amoreira. Não é, pois, por acaso, que $87 \%$ dos jovens inquiridos naquele bairro e $76 \%$ dos que o foram neste último, se autoposicionam na metade inferior da escala social. As geografias da injustiça encontram aqui um terreno fértil para a sua (re)produção.

Os jovens protagonistas pertencentes aos DRK e aos ValArt, por seu turno, têm intervindo na cidade usando o TO enquanto instrumento privilegiado. Todavia, fazem-no a partir de perspectivas distintas acerca daquilo que são os problemas mais prementes refletindo, efetivamente, o contexto socioespacial a partir do qual concebem política e artisticamente as peças de teatro que apresentam. Por um lado, os DRK, baseados no Alto da Cova da Moura, têm colocado a tônica sobre problemas como a discriminação e a estigmatização, as escolhas e as opções que os jovens afrodescendentes enfrentam numa sociedade que os marginaliza e exclui, as desigualdades socioeconômicas e os estereótipos culturais. Por outro, os ValArt, sediados no Vale da Amoreira, têm, por seu turno, direcionado a sua atenção para as problemáticas das relações de poder familiar e a subalternidade das mulheres, a sexualidade, a (des)igualdade de gênero e a vida dos adolescentes.

O envolvimento com o TO foi ajudando a perceber o modo como este opera enquanto instrumento de cidadania, ajudando-os a usarem as suas experiências, histórias e narrativas pessoais e contextuais para intervir social e politicamente. $\mathrm{Na}$ verdade, verificou-se também que, para os jovens protagonistas com quem falamos, a política precede sempre a arte, ou seja, consideram que fazem política, mas fazem-na usando a arte como instrumento privilegiado de comunicação e diálogo. Mais concretamente, o TO é usado para promover a consciencialização interpessoal e comunitária, para lançar alguma luz, esclarecer e elucidar acerca das con- 
dições existenciais presentes nos espaços urbanos em que intervêm estes jovens, em suma, para questionar a realidade (sub)urbana em que vivem. Não obstante, estão plenamente conscientes dos limites de sua ação, do alcance relativo de sua intervenção através da arte, das condições de precariedade em que desenvolvem o seu trabalho, bem como do tempo necessário para que este se possa consolidar e autonomizar.

No âmbito do TO enquanto sistema teatral e de suas manifestações concretas forjadas no Alto da Cova da Moura e no Vale da Amoreira, a injustiça encontra-se intrinsecamente relacionada a um conjunto vasto de relações econômicas e culturais estruturais tais como a exploração, a marginalização, a dominação cultural, a violência, o não reconhecimento e o desrespeito, que são abordados não a partir de teorizações abstratas e desvinculadas das vidas reais das pessoas que as sofrem na pele, mas sim a partir da identificação de suas manifestações concretas nos espaços urbanos em que se desenrolam as suas vidas cotidianas. A prática do TO contribui necessariamente para o combate a alguns dos efeitos mais nefastos da segregação urbana, como, por exemplo, a invisibilidade social e política a que estão sujeitas as pessoas que habitam o Alto da Cova da Moura e o Vale da Amoreira e a existência de fronteiras que separam espaços urbanos como estes do restante tecido urbano.

A análise levada a cabo mostra também que os jovens se tornam sujeitos políticos intervenientes, conscientes e críticos, mais capazes de questionar a realidade urbana que os rodeia, tornando-se, por vezes, referências importantes em suas comunidades. Paralelamente, tornam-se interlocutores privilegiados no processo de construção de uma rede de relações, sobretudo metropolitanas, entre espaços urbanos que partilham os mesmos problemas econômicos e culturais. Efetivamente, as relações de proximidade e os encontros propiciados pela prática artística dos diferentes grupos comunitários facilitam a reflexão, o diálogo, o debate e a aprendizagem coletiva entre diferentes entidades constitutivas da cidade contemporânea. Esta é, aliás, a escala privilegiada de sua intervenção, pois é a partir de suas vivências urbanas que intervêm social e politicamente. No entanto, os jovens protagonistas têm consciência plena - o que não significa que isso tenha reflexos na esfera das estratégias de atuação seguidas - de que o tipo de problemas que experienciam nos contextos geográficos de onde são oriundos, e que partilham com muitas outras pessoas, apresentam uma natureza eminentemente multiescalar. 


\section{Referências}

ABBING, Hans. Why are artists poor? The exceptional economy of the arts. Amsterdam: Amsterdam University Press, 2002.

ANDRÉ, Isabel; VALE, Mário. Lisboa: tensiones entre la ciudad y la metrópoli. BALBO, Marcello (Coord.). Europa: la ciudad central en el sistema urbano, p. 209-239. Quito: Olacchi, 2012.

BENITEZ, Hans. "The moment of testimonio is over": problemas teóricos y perspectivas de los estudios testimoniales. Íkala, Revista de Lenguage y Cultura, n. 15, p. 47-71, 2010.

BISHOP, Claire. Introduction. Viewers as producers. In: BISHOP, Claire (Ed.). Participation, p. 10-17. London; Cambridge (MA): Whitechapel; MIT Press, 2006.

BOAL, Augusto. A estética do oprimido. Rio de Janeiro: Fundação Nacional de Artes (Funarte), 2009.

- Hamlet and the baker's son: my life in theatre and politics. London: Routledge, 2001.

BORJA, Jordi. La ciudad conquistada. Madrid: Alianza Editorial, 2003.

BAVO. Always choose the worst option artistic resistance and the strategy of over-identification. In: BAVO (Ed.) Cultural activism today: the art of over-identification, p. 18-39. Roterdam: Episode Publishers, 2007.

CAPUCHA, Luís. Territórios da pobreza, onde é preciso voltar. Sociedade e Território, n. 30, p. 8-15, 2000.

CASTELLS, Manuel. The process of urban social change. In: CUTHBERT, Alexander (Ed.) Designing cities: critical readings in urban design, p. 23-27. Oxford (UK): Blackwell, 2003.

COHEN-CRUZ, Jan. Redefining the private: from personal storytelling to political act. In: COHEN-CRUZ, Jan; SCHUTZMAN, Mady (Eds.). A Boal companion: dialogues on theatre and cultural politics, p. 103-113. New York; London: Routledge, 2006.

CORREIA, André. Teatro fora dos teatros. Arte dramática na prisão, no jardim e no bairro. Revista Crítica de Ciências Sociais, n. 67, p. 55-73, 2003.

DUNCOMBE, Stephen. Notes from underground: zines and the politics of alternative culture. Bloomington (IN): Microcosm Publishing, 2008. 
FORTUNA, Carlos; FERREIRA, Claudino; ABREU, Paula. Espaço público urbano e cultura em Portugal. Revista Crítica de Ciências Sociais, n. 52/53, p. 85-117, 1998/1999.

GAT. Operação Vale da Amoreira: diagnóstico. Lisboa: INH, 2006.

GUERRA, Isabel. A cidade multicultural e multiétnica: gestão da diversidade e procura da democracia. In: LAGES, Mário Ferreira; MATOS, Artur Teodoro (Coords.). Portugal: percursos de interculturalidade 2, p. 97-118. Lisboa: Acime, 2008.

HAIG-BROWN, Celia. Creating spaces: testimonio, impossible knowledge, and academe. Qualitative Studies in Education, n. 16, p. 415-433, 2003.

HORTA, Ana. Contested citizenship: immigration politics and grassroots migrants' organizations in post-colonial Portugal. New York: Center for Migration Studies, 2004.

KANNGIESER, Anja. Breaking Out of the specialist "ghetto": performative encounters as participatory praxis in radical politics. Thamyris/Intersecting, n. 21, p. 115136, 2010.

KERSHAW, Baz. The politics of performance: radical theatre as cultural intervention. London; New York: Routledge, 1992.

LABORATORY OF INSURRECTIONARY IMAGINATION. A user's guide to the impossible. London: Labofii, 2010.

LACLAU, Ernesto; MOUFFE, Chantal (Eds). Hegemony and socialist strategy: towards a radical democratic politics. London, Verso, 2001.

LARSEN, Lars. Social æsthetics. In: BISHOP, Claire (Ed.). Participation, p. 172-183. London; Cambridge (MA): Whitechapel; MIT Press, 1999/2006.

LINDS, Warren. a journey in metaxis: theatre of the oppressed as enactivist praxis. NJ, n. 22, p. 71-85, 1998.

LOPES, Silvina. Precedências desajustadas. In: MAIA, Tomás (Org.). Persistência da obra: arte e política, p. 41-66. Lisboa: Assírio \& Alvim, 2011.

MALHEIROS, Jorge; MENDES, Manuela; BARBOSA, Carlos; SILVA, Sandra; SCHILTZ, Aline; VALA, Francisco. Espaços e expressões de conflito e tensão entre autóctones, minorias migrantes e não migrantes na área metropolitana de Lisboa. Lisboa: Acime, 2007. 
MALHEIROS, Jorge; VASCONCELOS, Lia; ALVES, Francisco (Coords). Operação Cova da Moura. Volume I "Diagnóstico para a intervenção sócio-territorial". Lisboa: INH, 2006.

MANCHEV, Boyan. A persistência das formas. Para uma nova política æstética. In: MAIA Tomás (Org.). Persistência da obra: arte e política, p. 29-40. Lisboa: Assírio \& Alvim, 2011.

MARCUSE, Peter; KEMPEN, Ronald. States, cities, and the partitioning of urban space. In: MARCUSE, Peter; KEMPEN, Ronald (Eds.). Of States and cities: the partitioning of urban space, p. 3-10. Oxford (UK): Oxford University Press, 2002.

MASSET, Delphine. Art et démocratie (Éditorial). Émulations, n. 9, p. 9-20, 2011.

MERRIFIELD, Andy; SWYNGEDOUW, Erik (Eds.). The urbanization of injustice. London: Lawrence \& Wishart, 1996.

MESKIMMON, Marsha. Contemporary art and the cosmopolitan imagination. London; New York: Routlege, 2011.

MOORE, Alan. Political economy as subject and form in contemporary art. Review of Radical Political Economics, n. 36, p. 471-486, 2004.

MOUFFE, Chantal. Artistic activism and agonistic spaces. Art \& Research - A Journal of Ideas, Contexts and Methods, v. 1, n. 2, p. 1-5, 2007.

- The democratic paradox. London: Verso, 2000.

MOUFFE, Chantal; DEUTSCHE, Rosalyn; JOSEPH, Branden; KEENAN, Thomas. Every form of art has a political dimension. Grey Room, n. 2, p. 98-125, 2001.

NAWRATEK, Krzysztof. City as a political idea. Plymouth (UK): University of Plymouth Press, 2011.

NEGRO, Francesca; CARVALHO, Manuela. Cidades: mundos de fragilidade e força. Próximo Futuro: II workshop de investigação - As Cidades. Lisboa: FCG, 2010.

NUNES, João. Teoria crítica, cultura e ciência: O(s) espaço(s) e o(s) conhecimento(s) da globalização. In: SANTOS, Boaventura de Sousa (Org.). Globalização: fatalidade ou utopia?, p. 297-338. Porto (PT): Afrontamento, 2001.

PAIS, José Machado. Lufa-lufa quotidiana: ensaios sobre cidade, cultura e vida urbana. Lisboa: ICS, 2010. 
PADILLA, Beatriz. Recriando identidades juvenis entre jovens de descendência africana na Área Metropolitana de Lisboa. In: PAIS, José Machado; BENDIT, René; FERREIRA, Vítor Sérgio (Orgs.). Jovens e Rumos, p. 159-180. Lisboa: ICS, 2011.

POIRIER, Jean; CLAPIER-VALLADON, Simone; RAYBAUT, Paul. Histórias de vida: teoria e prática. Oeiras (PT): Celta, 1999.

RANCIÈRE, Jacques. AEsthetics and its discontents. Cambridge (UK): Polity Press, 2009.

The æsthetic revolution and its outcomes: emplotments of autonomy and heteronomy. New Left Review, n. 14, p. 133-151, 2002.

RANDALL, Margaret. ¿Qué és y cómo se hace un testimonio? In: BEVERLEY, John; ACHUGAR, Hugo (Eds.). La voz del otro: testimonio, subalternidad y verdad narrativa, p. 33-57. Guatemala: Abrapalabra, 2002.

RIBEIRO, Luiz. Segregação residencial e políticas públicas: análise do espaço social da cidade na gestão do território. Cidades - Comunidades e Territórios, n. 6, p. 3350, 2003.

SANTOS, Maria (Coord.). Diagnóstico da população imigrante no concelho da Moita: desafios e potencialidades para o desenvolvimento local. Lisboa: Acidi, 2011.

SCHECHNER, Richard. A polity of its own called art?. In: CAMPBELL, Mary Schmidt; MARTIN, Randy (Eds.). Artistic citizenship: a public voice for the arts, p. 33-41. New York: Routledge, 2006.

SCHUTZMAN, Mady. Brechtian Schamanism: The political therapy of Augusto Boal. In: SCHUTZMAN, Mady; COHEN-CRUZ, Jan (Eds.). Playing Boal: theatre, therapy, activism, p. 137-155. London; New York: Routledge, 1994.

SCHUTZMAN, Mady; COHEN-CRUZ, Jan. Introduction. In: COHEN-CRUZ, Jan; SCHUTZMAN, Mady (Eds.). A Boal companion: dialogues on theatre and cultural politics, p. 1-9. New York; London: Routledge, 2006.

SELZ, Peter. Art of engagement: visual politics in California and beyond. Berkeley (CA): University of California Press, 2006.

SILVA, Manuel Carlos. Racismo e conflito interétnico: elementos para uma investigação. Revista Crítica de Ciências Sociais, n. 56, p. 61-79, 2000.

SOJA, Edward. Postmetropolis: critical studies of cities and regions. Oxford (UK): Blackwell Publishing, 2000. 
TUCKER, Kenneth. Workers of the world, enjoy! Asthetic politics from revolutionary syndicalism to the global justice movement. Philadelphia (PA): Temple University Press, 2010.

VASCONCELOS, Lia. Cova da Moura: uma experiência de intervenção sócio-territorial participada. Inforgeo, n. 20/21, p. 107-113, 2007.

VICENTE, Paula; REIS, Elizabeth; FERRÃO, Fátima. Sondagens: a amostragem como factor decisivo de qualidade. Lisboa: Edições Sílabo, 2001.

VIDAL, Carlos. Definição da arte política: o radicalismo, a desconstrução, o artifício e todos os seus paradoxos. Lisboa: Fenda, 1997.

WACQUANT, Loïc. Urban outcasts: a comparative sociology of advanced marginality. Cambridge (UK): Polity Press, 2008.

A estigmatização territorial na idade da marginalidade avançada. Sociologia: Revista do Departamento de Sociologia da FLUP, v. 1, n. 16, p. 251-268, 2006.

YOUNG, Iris. Justice and the politics of difference. New Jersey (NJ): Princeton University Press, 1990. 